\title{
Angiotensin-Converting Enzyme (ACE) Inhibitors and Pancreatitis: A Potential Dose-dependent Relationship
}

\author{
Murtaza S Hussain ${ }^{1}$, Smit S Deliwala ${ }^{1}$, Anoosha Ponnapalli ${ }^{1}$, Viraj Modi ${ }^{2}$, Ashok Kanugula ${ }^{1}$, Mamoon M Elbedawi $^{3}$, Ghassan Bachuwa $^{1}$ \\ ${ }^{1}$ Department of Internal Medicine, Michigan State University at Hurley Medical Center, Flint, MI, USA \\ ${ }^{2}$ New York Institute of Technology College of Osteopathic Medicine, Glen Head, NY, USA \\ ${ }^{3}$ Department of Internal Medicine - Division of Gastroenterology, Michigan State University at Hurley Medical Center, Flint, MI, USA
}

\section{Doi: 10.12890/2020_001956 - European Journal of Case Reports in Internal Medicine - @ EFIM 2020}

Received: 31/08/2020

Accepted: $15 / 09 / 2020$

Published: $28 / 10 / 2020$

How to cite this article: Hussain MS, Deliwala SS, Ponnapalli A, Modi V, Kanugula A, Elbedawi MM, Bachuwa G. Angiotensin-converting enzyme (ACE) inhibitors and pancreatitis: a potential dose-dependent relationship. EJCRIM 2020;7: doi:10.12890/2020_001956.

Conflicts of Interests: The Authors declare that there are no competing interests.

Acknowledgements: We would like to thank our librarian, Jennifer Godlesky, for a thorough literature search on the topic and the radiology department at Hurley Medical Center.

This article is licensed under a Commons Attribution Non-Commercial 4.0 License

\section{ABSTRACT}

Acute pancreatitis (AP) remains one of the most common causes of emergency department visits in the USA. The literature supports an

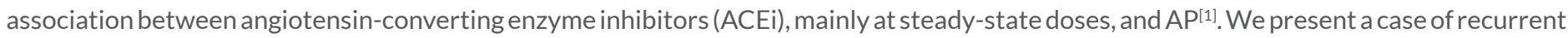
AP and pseudocyst formation following multiple ACEi dose adjustments after a steady-state period lasting for over a decade. Previous reports have rarely described ACEi-induced pancreatitis and pseudocyst development. ACEi can cause significant ductal obstruction ${ }^{[2]}$ and fluid retention due to its angioedema effects. Consequently, it may trigger AP complicated by pseudocyst formation. Therefore, ACEi administration must be considered in the appropriate clinical context.

\section{LEARNING POINTS}

- Although rare, ACEi is an emerging cause of drug-induced pancreatitis and often goes unrecognized.

- Multiple dose changes within a short period of time can lead to acute drug-induced pancreatitis (DIP), in addition to classic DIP caused by steady-state doses.

- ACEi-induced angioedema damages the ductal architecture and also has longer-lasting effects such as pseudocyst formation.

\section{KEYWORDS}

Acute pancreatitis, drug-induced pancreatitis, ACEi, recurrent acute pancreatitis, lisinopril

\section{INTRODUCTION}

Drug-induced pancreatitis (DIP) occurs in $0.1-2 \%$ of patients with AP and remains a diagnosis of exclusion. There are hundreds of offending agents, but ACEi are particularly important due to their numerous benefits and widespread use globally ${ }^{[3]}$. Thorough investigation of AP includes ruling out DIP among other causes. Although an association has been identified, ACEi-induced pancreatitis has rarely been described compared to reports implicating other drugs ${ }^{[1,4]}$. The relationship between dose modification and pancreatitis development has not been fully elucidated, representing a literature gap ${ }^{[5]}$. We report a case of recurrent AP ${ }^{[6]}$ and pseudocyst development in a patient whose dose was adjusted after a prolonged steady-state period. This report describes the typical presentation of DIP and discusses the pathophysiology of ACEi-induced AP. 


\section{CASE DESCRIPTION}

A 63-year old woman presented to our emergency department (ED) with a 7-day history of abdominal pain, nausea and anorexia (index admission). Her history included hypertension, diabetes, hyperlipidaemia, asthma and obesity. She was compliant on lisinopril $40 \mathrm{mg}$, atenolol $50 \mathrm{mg}$, hydrochlorothiazide (HCTZ) $25 \mathrm{mg}$, simvastatin $20 \mathrm{mg}$, ipratropium and insulin. She denied similar previous episodes or symptoms and did not use alcohol. She was haemodynamically stable, and physical examination only showed epigastric tenderness. Laboratory work-up revealed elevated lipase levels, consistent with acute pancreatitis. Hydration, analgesia and anti-emetics were given. Right upper quadrant ultrasound revealed no biliary pathology, while computed tomography (CT) and magnetic resonance cholangiopancreatography (MRCP) revealed a pseudocyst (Figs. 1 and 2), which had not been seen on previous abdominal imaging. The gastroenterology department was consulted and assisted in completing extensive haematological, metabolic, lipid and autoimmune profiling, which was negative.

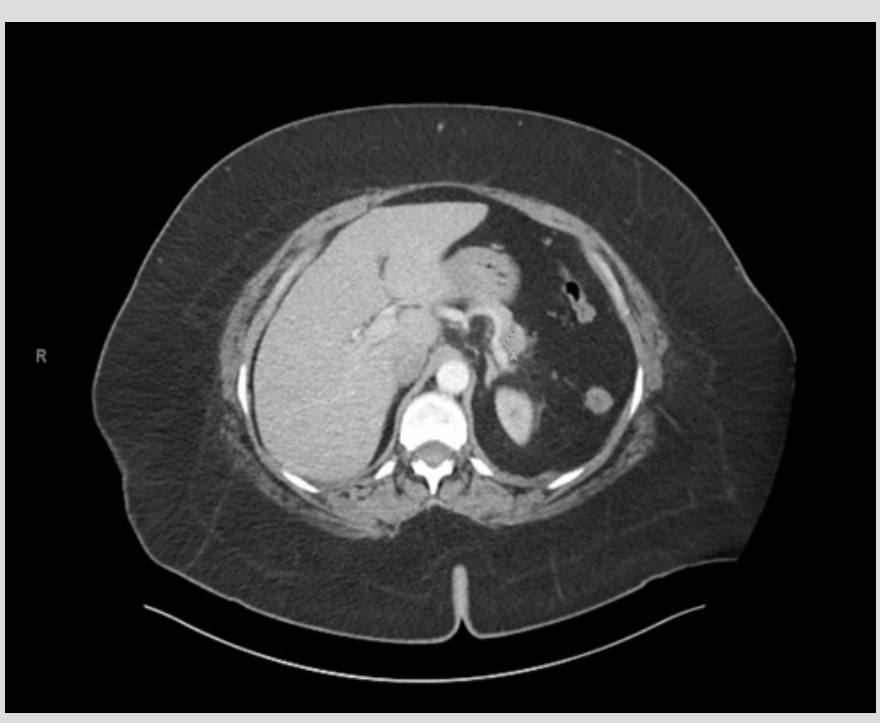

Figure 1. Computed tomography (CT) of the abdomen, revealing a $1.5 \mathrm{~cm}$ hypodensity in the pancreatic body consistent with a pseudocyst

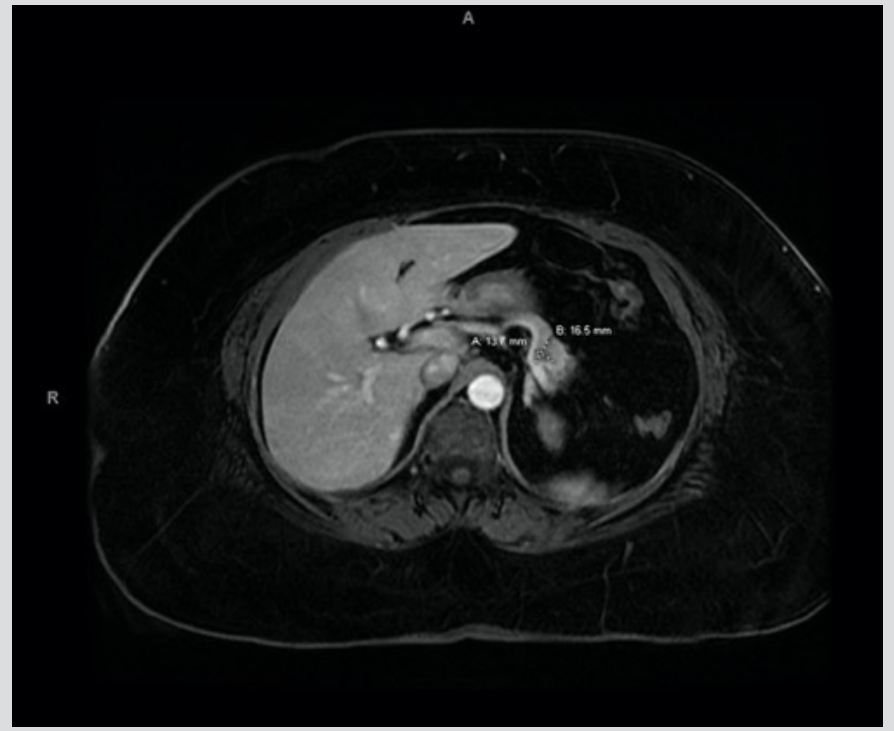

Figure 2. Magnetic resonance cholangiopancreatography (MRCP) with Omniscan revealing a $1.7 \mathrm{~cm} \times 1.4 \mathrm{~cm}$ hypoenhancement with a central cystic component

Once symptoms improved, hydrochlorothiazide and simvastatin as potential culprits were discontinued on patient discharge. Over the following weeks, the patient presented with two further episodes of pancreatitis and hypertensive urgency with residual pain, which was managed with pregabalin. At a follow-up visit, a chart review revealed previous interruption of her long-term medication regimen during an admission for asthma exacerbation and hypertensive urgency shortly before her index admission, which resulted in an increase in lisinopril from $10 \mathrm{mg}$ to $20 \mathrm{mg}$ and eventually $40 \mathrm{mg}$ at discharge. Lisinopril was discontinued as the final potential offender. At her 2 -month follow-up appointment, the patient reported no symptoms and the longest symptom-free period since episodes of AP began. Hepatobiliary trends and work-up findings are summarized in Tables 1 and 2.

\section{DISCUSSION}

The incidence of AP continues to increase and contributes an estimated $\$ 2$ billion to healthcare costs ${ }^{[7]}$. Albeit responsible for a small percentage of these costs, the contribution of DIP to the overall burden can be easily reduced. Since ACEi is the first-line treatment in patients with cardiovascular pathology, ACEi-associated AP is reported in the literature in the form of case reports ${ }^{[1,4]}$ and case-control studies ${ }^{[5,8]}$. The length of time between ACEi administration and the development of AP resulting in pancreatic angioedema ranges from hours ${ }^{[9,10]}$ to years ${ }^{[11]}$. It is postulated that bradykinin accumulation following ACEi administration increases vascular permeability, with angioedema leading to ductal obstruction ${ }^{[2]}$. This occlusion results in the entrapment of pancreatic enzymes and toxins within the pancreas which autodigest surrounding tissues ${ }^{[12]}$. Angiotensin II receptors are hypothesized to regulate pancreatic microcirculation and secretion, and the absence of receptor activation may exacerbate AP symptoms even further ${ }^{[13]}$. At the same time, ACEi can induce hypoglycaemia that has direct toxic effects on the pancreatic ducts ${ }^{[9]}$. Specific characteristics like older age and African American ethnicity ${ }^{[11]}$, as in our 
patient, may result in higher predisposition to ACEi angioedema ${ }^{[14]}$. Our patient's history of uncontrolled diabetes could have led to intrinsic pancreatic changes predisposing her to insult by any potential offenders ${ }^{[12,14]}$. To support this theory, our patient's Naranjo Adverse Drug Probability score of $6^{[15]}$ and a class III DIP designation ${ }^{[16]}$ suggest an adverse drug reaction, although these scores may be under-represented as confirmatory methods such as re-challenge are unethical ${ }^{[9]}$. Our patient had been taking lisinopril for 15 years and was stable on $10 \mathrm{mg}$. Sudden adjustments in ACEi dosage, with an up-titration towards the maximum dose, can increase the burden of bradykinin, overwhelming compensatory mechanisms. These sequences of changes were seen in our patient's regimen prior to her index admission, when she was on $40 \mathrm{mg}$ lisinopril at presentation.

An abdominal CT scan from years previously did not show any evidence of radiographic pancreatitis or pseudocyst formation. Since pseudocysts develop from disturbances in the pancreatic duct and extravasation of secretions ${ }^{[17]}$, the initial fluctuations in lisinopril could have led to robust development of oedema and pseudocyst formation, exhibited on the index admission. The severity of ACEi-associated AP ranges from mild to severe. Most cases are mild, with a paucity of necrotic ${ }^{[18]}$ or fulminant ${ }^{[19]}$ cases; our patient's pseudocyst development placed her in the medium category. Although DIP is a rare entity, patients with AP of unexplained aetiology warrant careful review, and discontinuation and replacement of suspicious medications. Angiotensin receptor blockers (ARB) may be an alternative due to the lower risk of $\mathrm{AP}^{[20]}$. This case demonstrates that clinicians should be aware of the consequences of ACEi dose modification.

\begin{tabular}{|l|l|l|l|}
\hline & Admission 1 & Admission 2 & Admission 3 \\
\hline Lipase & $453 \mathrm{U} / \mathrm{l}$ & $314 \mathrm{U} / \mathrm{l}$ & $313 \mathrm{U} / \mathrm{l}$ \\
\hline AST & $14 \mathrm{U} / \mathrm{l}$ & $30 \mathrm{U} / \mathrm{l}$ & $13 \mathrm{U} / \mathrm{l}$ \\
\hline ALT & $11 \mathrm{U} / \mathrm{l}$ & $26 \mathrm{U} / \mathrm{l}$ & $20 \mathrm{U} / \mathrm{l}$ \\
\hline ALP & $87 \mathrm{U} / \mathrm{l}$ & $73 \mathrm{U} / \mathrm{l}$ & $71 \mathrm{U} / \mathrm{l}$ \\
\hline Total bilirubin & $0.5 \mathrm{mg} / \mathrm{dl}$ & $0.5 \mathrm{mg} / \mathrm{dl}$ & $0.4 \mathrm{mg} / \mathrm{dl}$ \\
\hline White blood cell count & $13.2 \mathrm{~K} / \mu \mathrm{l}$ & $9.2 \mathrm{~K} / \mu \mathrm{l}$ & $6.4 \mathrm{~K} / \mu \mathrm{l}$ \\
\hline
\end{tabular}

Table 1. Hepatobiliary test results across admissions

\begin{tabular}{|l|l|}
\hline ESR & $54 \mathrm{~mm} / \mathrm{hr}$ \\
\hline CRP & $9.9 \mathrm{mg} / \mathrm{l}$ \\
\hline ANA & Negative \\
\hline IgG & $556 \mathrm{mg} / \mathrm{dl}$ \\
\hline Triglycerides & $107 \mathrm{mg} / \mathrm{dl}$ \\
\hline Total cholesterol & $157 \mathrm{mg} / \mathrm{dl}$ \\
\hline Calcium & $9.1 \mathrm{mg} / \mathrm{dl}$ \\
\hline Thyroid stimulating hormone (TSH) & $2.63 \mu / \mathrm{l} / \mathrm{ml}$ \\
\hline
\end{tabular}

Table 2. Pertinent laboratory data from index admission for acute pancreatitis 


\section{REFERENCES}

1. Thumma S, Errico K, Manchala V, Mattana J. Lisinopril-induced acute pancreatitis. Am J Ther 2019;26(4):e555-e558.

2. Dabaghi S. ACE inhibitors and pancreatitis. Ann Intern Med 1991;115(4):330-331.

3. Mahmoudpour SH, Asselbergs FW, Souverein PC, de Boer A, Maitland-van der Zee AH. Prescription patterns of angiotensin-converting enzyme inhibitors for various indications: a UK population-based study. Br J Clin Pharmacol 2018;84(10):2365-2372.

4. Singh S. Angiotensin-converting enzyme (ACE) inhibitor-induced acute pancreatitis: in search of the evidence. South Med J 2006;99(12):1327-1329.

5. Kuoppala J, Enlund H, Pulkkinen J, Kastarinen H, Jyrkkä J, Happonen P, et al. ACE inhibitors and the risk of acute pancreatitis-a population-based case-control study. Pharmacoepidemiol Drug Saf 2017;26(7):853-857.

6. Kanbay M, Selcuk H, Yilmaz U, Boyacioglu S. Recurrent acute pancreatitis probably secondary to lisinopril. South Med J 2006;99(12):1388-1390.

7. Peery AF, Dellon ES, Lund J, Crockett SD, McGowan CE, Bulsiewicz WJ, et al. Burden of gastrointestinal disease in the United States: 2012 update. Gastroenterology 2012;143(5):1179-1187.

8. Eland IA, Sundström A, Velo GP, Andersen M, Sturkenboom MCJM, Langman MJS, et al. Antihypertensive medication and the risk of acute pancreatitis: the European casecontrol study on drug-induced acute pancreatitis (EDIP). Scand J Gastroenterol 2006;41(12):1484-1490.

9. Gershon T, Olshaker JS. Acute pancreatitis following lisinopril re-challenge. Am J Emerg Med 1998;16(5):523-524

10. Tosun E, Oksuzofflu B, Topalofflu O. Relationship between acute pancreatitis and ACE inhibitors. Acta Cardiol 2004;59(5):571-572.

11. Gorsane I, Ayed TB, Aoudia R, Kaaroud H, Hamida FB, Harzallah A, et al. Simultaneous acute pancreatitis and angioedema associated with angiotensin-converting enzyme inhibitor. Saudi J Kidney Dis Transpl 2019;30(6):1479-1484.

12. Bouffard L, Papirakis M-E, Maheux P. Enalapril increases the local extravasation of macromolecules and nitric oxide synthase in pancreas of the fructose-fed insulin-resistant rat model. Pancreas 2006;33(4):418-424.

13. Jones MR, Hall OM, Kaye AM, Kaye AD. Drug-induced acute pancreatitis: a review. Ochsner J 2015;15(1):45-51.

14. Brown KV, Khan AZ, Paterson IM. Lisinopril-induced acute pancreatitis. J R Army Med Corps 2007;153(3):191-192.

15. Naranjo CA, Busto U, Sellers EM, Sandor P, Ruiz I, Roberts EA, et al. A method for estimating the probability of adverse drug reactions. Clin Pharmacol Ther 1981;30(2):239-245.

16. Badalov N, Baradarian R, Iswara K, Li J, Steinberg W, Tenner S. Drug-induced acute pancreatitis: an evidence-based review. Clin Gastroenterol Hepatol 2007;5(6):648-661.

17. Habashi S, Draganov PV. Pancreatic pseudocyst. World J Gastroenterol 2009;15(1):38.

18. Anagnostopoulos GK, Kostopoulos P, Tsiakos S, Margantinis G, Arvanitidis D. Fulminant pancreatitis associated with ramipril therapy. Pancreas 2003;27(3):278-279.

19. Standridge JB. Fulminant pancreatitis associated with lisinopril therapy. South Med J 1994;87(2):179-181.

20. Bexelius TS, Ljung R, Mattsson F, Lu Y, Lindblad M. Angiotensin II receptor blockers and risk of acute pancreatitis-a population based case-control study in Sweden. BMC Gastroenterol 2017;17(1):36. 